\title{
Influence of Cultivar and Planting Material on Soluble Dry Matter Content of Dahlia Tuberous Roots
}

\author{
Ioana CIOBANU (MOLDOVAN), Maria CANTOR*),Erzsebet BUTA, Tincuța GOCAN, Ioana CRIŞAN \\ Faculty of Horticulture, University of Agricultural Sciences and Veterinary Medicine, Mănăştur Street \\ 3-5, 400372, Cluj-Napoca, Romania \\ *)Corresponding author, e-mail: marcantor@yahoo.com
}

BulletinUASVM Horticulture 73(2) / 2016

Print ISSN 1843-5254, Electronic ISSN 1843-5394

DOI:10.15835/buasvmcn-hort:12241

\begin{abstract}
The aim of present paper was to study the influence of the planting material (forced and unforced tuberous roots), and of the cultivar on the average soluble dry matter content (\%) from Dahlia tuberous roots at harvest. Also, there were determined a series of relationships between soluble dry matter content and main plant characteristics, like average shoots per plant and average weight of the tuberous roots at harvest time. The study was conducted for two years at University of Agricultural Sciences and Veterinary Medicine Cluj-Napoca on seven cultivars of Dahlia hybrida 'cactus' type: 'Kennemerland', 'TsukiYori No Sisha', 'Hayley Jane', 'Purple Gem', 'Star Favourite', 'Park Princess' and 'Friquolet'. Based on the results obtained it can be concluded that the forcing of the tuberous roots affected the accumulation of soluble dry matter content at dahlia tubers, but it also depends on the cultivar. The highest content of soluble dry matter was at following cultivars 'Star Favourite' /forced tuberous roots (25.47\%), 'TsukiYori No Sisha'/unforced tuberous roots (24.80\%), 'Kennemerland'/unforced tuberous roots (24.27\%), 'Hayley Jane'/forced tuberous roots (23.97\%), and 'TsukiYori No Sisha'/forced tuberous roots (22.57\%). These dahlia cultivars can be recommended for inulin extraction.
\end{abstract}

Keywords: planting material, semi-rustic geophytes, soluble dry matter, tuberous roots.

\section{INTRODUCTION}

Dahlias are one of the most important cut flowers and also used as garden flower (Jamil and Gul, 2002) with 'cactus' type cultivars being the most desirable and preferred by costumers from around the world (Şelaru, 2007; https://www. gardenia.net). Also Dahlia is valuable for the inulin that has utilizations in medicine and food industry (Traynor et al., 2006; Zubaidah and Akhadiana, 2013; http://www.botanical.com).

Currently, the main global sources of commercial inulin are the fleshy roots of Dahlia sp., Cichorium intybus L. (chicory) and also the tubers of Helianthus tuberosus L. (Jerusalem artichoke). All of these species are from the Asteraceae family and present inulin in their underground storage organs up to $75 \%$ from the dry matter (Machado et al., 1998). It was determined in previous studies that Dahlia tubers are richer in inulin than other species like gembili and yam, also having a higher solubility (Zubaidah and Akhadiana, 2013).

The relationships between refractometer values and total sugar content (polysaccharides such as inulin) that could permit utilization of refractometer values as screening index to select genotypes for high inulin content was researched in the past for Cichorium intybus and Helianthus tuberosus (Baldini et al., 2000; Van Waes et al., 1998).

Based on the literature and researches cited above, it can be said that inulin comprises for an important part of the dry matter of Dahlia 
tuberous roots. Also it is a fraction measurable as soluble dry matter using a refractometer, and these determinations are able to provide a good estimation of total sugar content in tuberous roots.

Dry matter in Dahlia tubers is in fact a rich inulin reserve of the plant (Machado et al., 1998) that ensures the perennity by supplying nourishment for the development of the new shoots that form when the plant is entering in vegetation, with direct influence on the vigor of the plant in the first stages of growth.

In the case of the forced Dahlia plants, a part of the dry matter found in tuberous roots stored for winter, is utilized for the early entering in vegetation prior to planting compared to the unforced tuberous roots. Thus, it is considered that at planting time, the tuberous roots that were not forced have a slightly higher content in dry matter than the tuberous roots that were forced. In this regard, it can be punctuated that storage conditions of tuberous roots also significantly affects quality of tuberous roots, including mass loss as it was observed for Dahlia in previous studies (Ciobanu et al., 2015) as well as for Jerusalem artichoke (Danilčenko et al., 2008).

It is known that in similar way as it is the case for other species with tubers like Jerusalem artichoke (Helianthus tuberosus) (Fuchs, 1993), early planting and though analogy for Dahlia the forcing, determines the plant to start the assimilation processes earlier by developing a luxuriant vegetative partearly. Either early planting or forcing (depending on species) determines the plant to have a longer vegetation period and could ultimately cause a higher accumulation of reserve substances in tubers compared with the plants that had a shorter vegetation period, as it is the case for unforced Dahlia tuberous roots.

Due to the importance of carbohydrates (like inulin) stored in the tuberous roots, the cultivars that present a higher content of dry matter and soluble solids could be considered more valuable like in the case of Jerusalem artichoke (Helianthus tuberosus) (Baldini et al., 2000; Fuchs, 1993; Stauffer et al., 1980), oca (Oxalis tuberosa)(Lim, 2016).

Because of the importance that environmental and cultural factors have on the content of the modified roots, these are carefully researched. In this regards, it can be mentioned that cultivation system have influence on the accumulation of dry matter in different plant organs of Paeonia lactiflora (Sun et al., 2014).

From the cultural factors, the present study concentrates on determining the influence of the cultivation particularities, represented by starting the crop either with forced tuberous roots or unforced tuberous roots, on the content of soluble dry matter of Dahlia tuberous roots. Also relationships between these determinations and some vegetative characteristics were analyzed. The aim of the entire study was the identification of some valuable Dahlia cultivars and the best planting material to use for crops destined for processing and inulin extraction.

\section{MATERIALS AND METHODS}

The biologic material was imported from Holland, and was represented by seven cultivars of Dahlia hybrida with cactus type flower (factor A): $a_{1}$ - 'Kennemerland', $a_{2}$ - 'TsukiYori No Sisha', $a_{3}$ - 'Hayley Jane', $\mathrm{a}_{4}$ - 'Purple Gem', $\mathrm{a}_{5}$ - 'Star Favorite', $a_{6}$ - 'Park Princess' and $a_{7}$ - 'Friquolet'. In the experimental field, situated in the Agrobotanical Garden of the University of Agricultural Sciences and Veterinary Medicine Cluj-Napoca, have been used two types of plant material (factor B): $b_{1}-$ tuberous roots started earlier in greenhouse and then planted in the open field; $b_{2}$-tuberous roots that were not forced prior to planting in the field. By combining these two experimental factors with seven, respectively two levels, resulted 14 variants that were settled in a completely randomized block design with three replications (Ardelean et al., 2007). On each repetition were used three tuberous roots per variant, 21 per repetition, respectively 63 tuberous roots on experimental variant.

Forcing of the tuberous roots was conducted in the didactic greenhouse starting in 19 March 2015. The tuberous roots were planted in plastic pots with a capacity of two litres each. The biologic material (both forced and unforced) was planted on 12 May 2015 in the field. The observations and analyses were made in 2015-2016.

Biometric measurements were made during vegetation period. In autumn the tuberous roots were harvested from the field and the content of soluble dry matter was determined using Zeiss Refractometer (Fig. 1). Statistical analysis was performed using Duncan Multiple Range Test at PQ 0.05, and the correlation between the soluble 


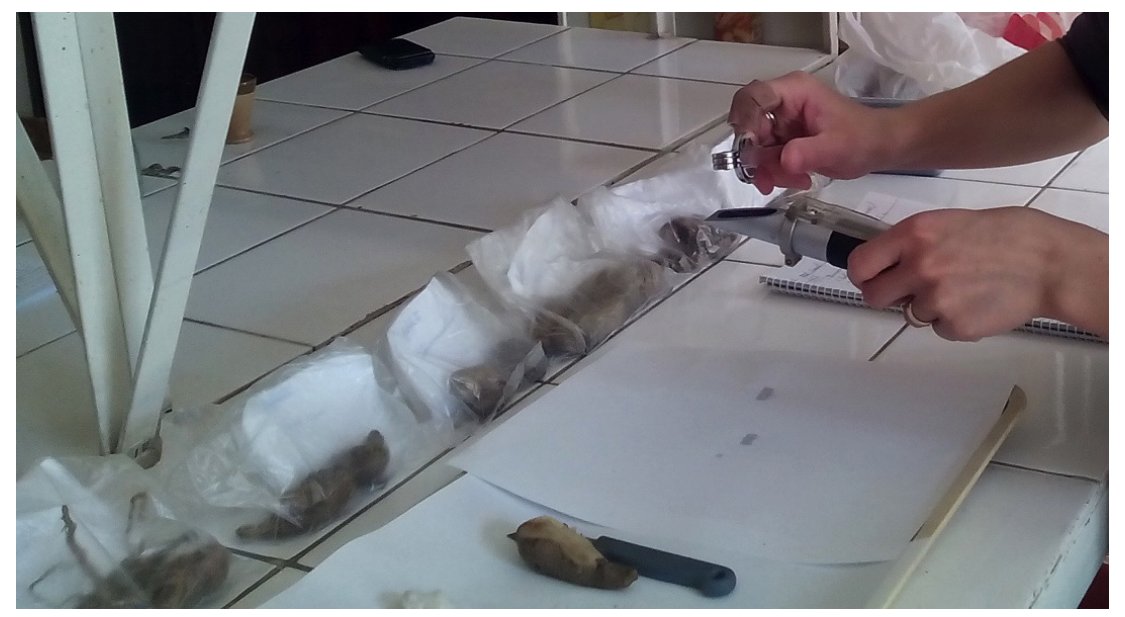

Fig. 1. Determination of soluble dry matter content of Dahlia tuberous roots using refractometer (Source: Original)

dry matter and the plant characteristics were determined using linear regression (Ardelean et al., 2007).

\section{RESULTS AND DISCUSSION \\ The average soluble dry matter content (\%) of the Dahlia tuberous roots}

Analyzing the Tab. 1 it can be observed that for the cultivars 'Hayley Jane', 'Star Favourite' and 'Friquolet', the value of the average soluble dry matter was lower for the unforced tuberous roots. Significant differences were registered for the variants $\mathrm{V}_{3}(23.97 \%), \mathrm{V}_{10}(15.13 \%), \mathrm{V}_{5}(25.47 \%)$ and $V_{12}(15.83 \%)$, while the variants $V_{7}(16.87 \%)$, $\mathrm{V}_{14}(11.63 \%)$ do not present significant differences.

Compared with the variants $\mathrm{V}_{3}$ - 'Hayley Jane' (23.97 \%), $V_{5}$ - 'Star Favourite' (25.47 \%) and $\mathrm{V}_{7}$ - 'Friqoulet' (16.87\%), the variants $\mathrm{V}_{1}$ 'Kennemerland' (16.43\%), $V_{2}$ - 'TsukiYori No Sisha' (22.57\%), $V_{4}$ - 'Purple Gem' (13.10\%), V - 'Park Princess' (14.90\%) presented a lower content of soluble dry matter in the forced tuberous roots, concluding that this method is not beneficial for these cultivars in regards with the soluble dry matter content at harvest.

A valuable cultivar was identified in the case of 'TsukiYori No Sisha', which compared with the other six cultivars studied, had a higher average content of soluble dry matter for both types of planting material: forced and unforced. The variants $V_{2}$ - 'TsukiYori No Sisha'/forced tuberous roots $(22.57 \%)$ and $V_{9}$ - 'TsukiYori No Sisha'/ unforced tuberous roots $(24.80 \%)$ are non- significant statistically different, but are different in value.

The variants $V_{14}$ - 'Friqoulet'/unforced tuberous roots (11.63\%), $\mathrm{V}_{4}$ - 'Purple Gem'/forced tuberous roots $(13.10 \%)$ and $V_{6}$ - 'Park Princess' / forced tuberous roots (14.90\%) are significantly different compared to variants $\mathrm{V}_{2}, \mathrm{~V}_{3}, \mathrm{~V}_{5}, \mathrm{~V}_{8}, \mathrm{~V}_{9}, \mathrm{~V}_{11 \text {, }}$ $\mathrm{V}_{13}$.

Similar with these results, Baldini et al. (2000) also found a large range of variability in the Helianthus tuberosus genotypes they studied using the same refractometer method, obtaining a mean value of $22.9 \pm 6.4$ for soluble solids. The refractometer determinations of soluble solids in tubers obtained by them were between $10-25 \%$ at harvest time (Sept.-Nov.). They also found that refractometrically measured solids expressed as the Brix-value, exhibited a significant positive relationship with the tuber inulin content $\left(0.90^{* *}\right.$ and $0.85^{* *}, \mathrm{n}=6$ ) confirming its suitability as a fast screening method in assessing inulin rich genotypes, avoiding time consuming and expensive laboratory analysis.

Relationship between average soluble dry matter content (\%) of tuberous roots of Dahlia cultivars and average shoots per plant

The regression line corresponding to the variants belonging to forced tuberous roots, presents a negative descending slope. The correlation coefficient $\left(R^{2}=0.0171\right)$ and regression coefficient $\left(b_{y x}=-0.0293\right)$ are not significant, with points scattered far either side of the regression line. In the Fig. 2 can be observed that average 
Tab. 1. The influence of Dahlia planting material on the average soluble dry matter content (\%) of tuberous roots at harvest

\begin{tabular}{|c|c|c|c|}
\hline Variant No. & Planting material & Cultivar & Average soluble dry matter content (\%) \\
\hline $\mathrm{V}_{1}$ & \multirow{7}{*}{$\begin{array}{l}\text { Forced tuberous } \\
\text { roots }\end{array}$} & 'Kennemerland' & 16.43 bcde \\
\hline $\mathrm{V}_{2}$ & & 'TsukiYori No Sisha' & $22.57 \mathrm{abc}$ \\
\hline $\mathrm{V}_{3}$ & & 'Hayley Jane' & $23.97 \mathrm{abc}$ \\
\hline $\mathrm{V}_{4}$ & & 'Purple Gem' & $13.10 \mathrm{e}$ \\
\hline $\mathrm{V}_{5}$ & & 'Star Favourite' & $25.47 \mathrm{a}$ \\
\hline$V_{6}$ & & 'Park Princess' & $14.90 \mathrm{e}$ \\
\hline $\mathrm{V}_{7}$ & & 'Friquolet' & 16.87 bcde \\
\hline $\mathrm{V}_{8}$ & \multirow{7}{*}{$\begin{array}{l}\text { Unforced tuberous } \\
\text { roots }\end{array}$} & 'Kennemerland' & $24.27 \mathrm{ab}$ \\
\hline $\mathrm{V}_{9}$ & & ‘TsukiYori No Sisha' & $24.80 \mathrm{ab}$ \\
\hline $\mathrm{V}_{10}$ & & 'Hayley Jane' & $15.13 \mathrm{de}$ \\
\hline$V_{11}$ & & 'Purple Gem' & $19.63 \mathrm{abcd}$ \\
\hline $\mathrm{V}_{12}$ & & 'Star Favourite' & $15.83 \mathrm{cde}$ \\
\hline$V_{13}$ & & 'Park Princess' & $20.23 \mathrm{abc}$ \\
\hline$V_{14}$ & & 'Friquolet' & $11.63 \mathrm{e}$ \\
\hline
\end{tabular}

number of shoots per plant is not a trait that influences the accumulation of soluble dry matter in tuberous roots of Dahlia. Forcing had a favorable effect on the accumulation of higher average soluble dry matter content for the cultivars: 'Star Favourite' (25.47\% soluble dry matter and an average number of 2.99 shoots per plant), 'Hayley Jane' $(23.97 \%$ soluble dry matter and a number of 3 shoots per plant) and 'TsukiYori No Sisha' (22.57 $\%$ soluble dry matter and a number of 4.55 shoots per plant).

Following the relationship between the average content in soluble dry matter (\%) of the tuberous roots and the average number of shoots per plant for the unforced planting material presented in Fig. 2, can be observed that the regression line has a positive ascending slope. The regression coefficient $\left(b_{y x}=0.152\right)$ is positive and distinct significant, thus the soluble dry matter from tuberous roots of Dahlia could increase even if the average number of shoots per plant decreases like for the cultivar 'Park Princess' (20.23\% soluble dry matter and average shoots number per plant of 1.22). The value of ' $t$ ' certified statistically the result, the transgression probability being of $0.29 \%$, between $\mathrm{P}_{0.1 \%}$ and $\mathrm{P}_{5.6 \%}$ (Ardelean et al., 2007).

In a study conducted on several cassava cultivars with contrasting growth habits in order to study the crop performance, Holmes and Wilson
(2003) found significant correlation coefficients between node number $(\mathrm{r}=0.64)$, leaf number (0.56), leaf area $(r=0.69)$, and total dry weight over all cultivars studied.

Funell et al. (2002) studying the Zantedeschia tubers growth and dry mass in regards with high photosynthetic photon flux regime, found that increases in tuber growth are correlated with increased net assimilation rate due to efficiency of dry matter accumulation by the leaf area.

Relationship between average soluble dry matter content (\%) of tuberous roots of Dahlia cultivars and average weight at harvest

The Fig. 3 reveals the relationships between soluble dry matter content (\%) of the tuberous roots and the weight of the tuberous roots at harvest time. For the forced plant material of the cultivars 'TsukiYori No Sisha', 'Hayley Jane' and 'Star Favourite', it can be said that the weight of the tuberous roots increases once with the increase of soluble dry matter content (\%) with the exception of 'Kennemerland' that registered a weight of 0.9 $\mathrm{kg}$ and $16.43 \%$. Comparing the calculated value of ' $t$ ' for the regression analyzed, with the degree of freedom $\mathrm{GL}=5$ and $\mathrm{t}=0.87$, the transgression probability is of $0.87 \%$, between $\mathrm{P}_{0.1 \%}$ and $\mathrm{P}_{1 \%}$ (Ardelean et al., 2007). Thus, the regression coefficient calculated is not significant and the regression line has a positive ascending slope. 


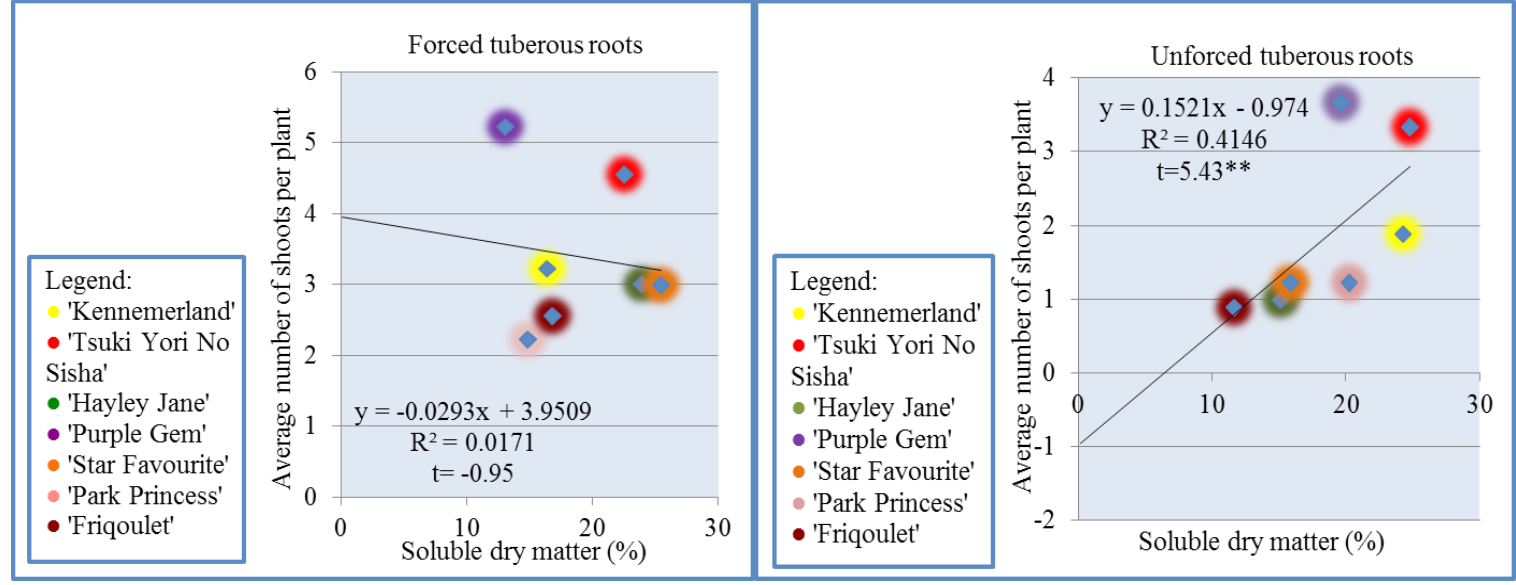

Fig. 2. Correlation equation and correlation line for average soluble dry matter content (\%) and average number of shoots per plant

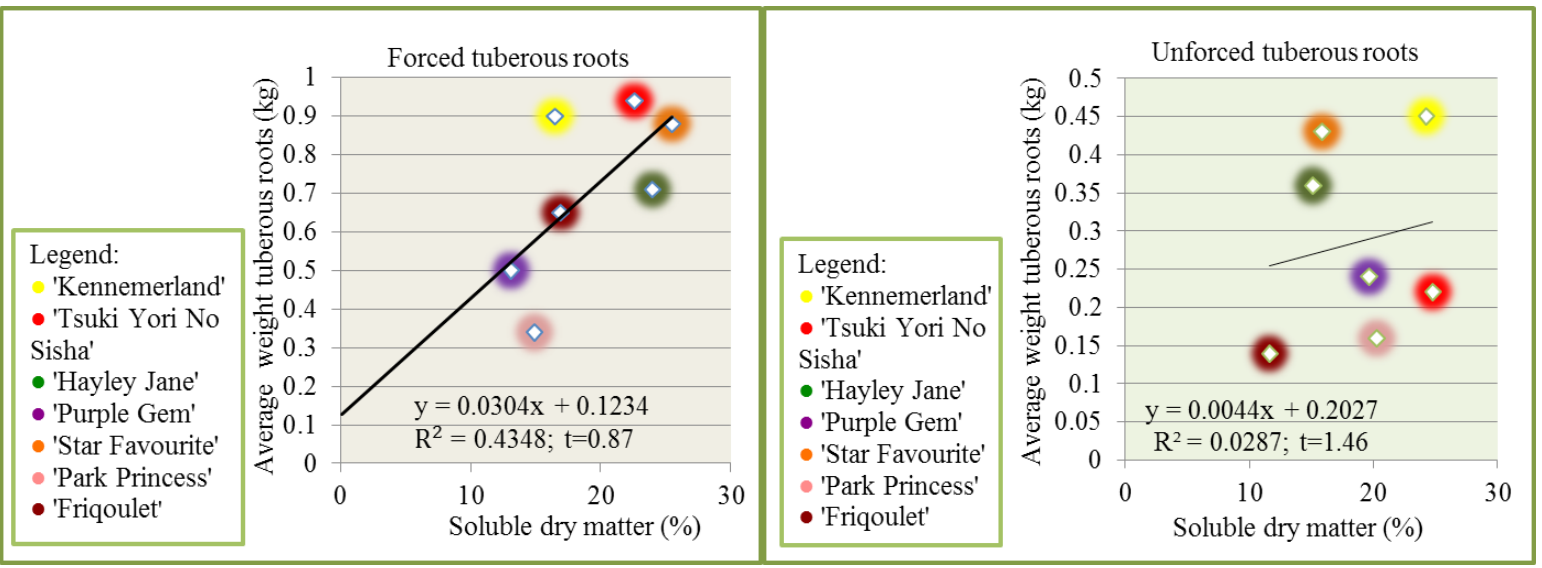

Fig. 3. Correlation equation and correlation line for average soluble dry matter content (\%) of the tuberous roots and the average weight of tubers at harvest $(\mathrm{kg})$

Researching similar parameters, Teye et al. (2011) observed a perfect correlation $\left(\mathrm{R}^{2}=0.9979\right)$ between specific gravity and dry matter content of cassava tubers.

For the variant belonging to the unforced planting material, the soluble dry matter content $(\%)$ is not influenced by the weight of the tuberous roots. The value of the correlation coefficient and of the regression coefficient for these characters is positive but non-significant.

Van Waes et al. (1998), found a relationship between total soluble sugars detected by refractometer and the inulin content in the plant organs in case of chicory roots. Thus, based on determination of the refractive index of the chicory root juice by refractometer, they proved that this analysis gives a good estimation of the total sugar content $(\mathrm{r}=0.85 ; \mathrm{RSD}=3.8 \%)$.
Proctor and Sullivan (2013) studying the effect of sowing depth from 10-100 mm over the dry substance of American ginseng (Panax quinquefolius L.) obtained the following equations for regression: $\operatorname{root}\left(\mathrm{y}=129.2-0.475 \mathrm{x}, \mathrm{R}^{2}=\right.$ $0.62)$, leaf $\left(y=41.1-0.76 x, R^{2}=0.66\right)$ stem $(y=$ $10.72+0.69 x, R^{2}=1.0$ ).

Both in Figure 2 and 3 can be seen that the cultivar 'TsukiYori No Sisha' for both traits studied presented high and close values for the soluble dry matter content.

\section{CONCLUSION}

In the present research work, it was demonstrated that for the cultivars 'Star Favourite' (25.47\%), 'Hayley Jane' (23.97\%), 'TsukiYori No Sisha' (22.57 \%) the presence of a well-developed vegetative part early had a beneficial influence on 
the storage of a higher soluble dry matter content, while for the cultivars 'TsukiYori No Sisha' (24.80 $\%)$, 'Kennemerland' (24.27\%), 'Park Princess' (20.23\%) using tuberous roots that were unforced prior to plating was in favor of accumulation of higher soluble dry matter content.

Following the relationships settled between the average soluble dry matter content of the tuberous roots and the average number of shoots per plant, respectively the average weight of the tuberous roots at harvest, it can be said that the correlations are imperfect because the cloud of data points is very scattered. For the forced planting material as well as for unforced planting material, the average number of shoots per plant it is not a character that influences the accumulation of soluble dry matter in the tuberous roots of Dahlia.

A positive influence on the content of soluble dry matter in tuberous roots is given by the weight of the forced tuberous roots at harvest time in the case of cultivars: 'Star Favourite', 'Hayley Jane' and 'TsukiYori No Sisha', with the exception of 'Kennemerland'.

Based on the results can be concluded that forcing of the tuberous roots can influence in different ways the Dahlia cultivars. For the horticultural producers interested in cultivation of Dahlia for inulin extraction, it is recommended to start the crops with the following cultivars: 'Star Favourite'/forced tuberous roots, 'TsukiYori No Sisha'/unforced tuberous roots, 'Kennemerland'/ unforced tuberous roots, 'Hayley Jane'/forced tuberous roots.

\section{REFERENCES}

1. Ardelean M, Sestraş R, Cordea M (2007). Horticultural experimental design. Ed. AcademicPres, Cluj - Napoca, 24-26, 72-74.

2. Baldini M, Danuso F, Turi M, Vannozzi GP (2000) Variability for characters related to inulin accumulation in topinambur (Helianthus tuberosus L.). 15th ISC Toulouse Proceedings.

3. Ciobanu I, Buta E, Husti A, Cantor M (2015). Research regarding the influence of cultivar and storage substrate at Dahlia variabilis cactus type. Agriculture - Science and Practice 3-4(95-96).

4. Danilčenko $\mathrm{H}$, Jarienė E, Aleknavičienė P, Gajewski M (2008). Quality of Jerusalem Artichoke (Helianthus tuberosus L.) Tubers in Relation to Storage Conditions. Not. Bot. Hort. Agrobot. Cluj, 36(2):23-27.

5. Fuchs A (1993). Inulin and Inulin-containing Crops. Studies in Plant Science 3:16-18.

6. Funnell KA, Hewett EW, Plummer JA, Warrington IJ (2002). Tuber dry-matter accumulation of Zantedeschia in response to temperature and photosynthetic photon flux. The Journal of Horticultural Science and Biotechnology 77:4.

7. Holmes EB, Wilson LA (2003). Total dry matter production, tuber yield, and yield components of six local cassava cultivars in Trinidad. 4th Tropical Root Crops Symposium Proceedings, 84-88.

8. Jamil AM, Gul S (2002). Evaluation of Exotic Cultivars of Dahlia (Dahlia coccinea) under Rawalakot Conditions. University College of Agriculture, Asian Journal of Plant1 5: 565-66.

9. Lim TK (2016). Edible Medicinal and Non-medicinal plants: modified stems, roots and bulbs. Springer International Publishing Switzerland 11, 141.

10. Machado de Carvalho MA, Pinto MM, Figueiredo-Ribeiro RCL (1998). Inulin production by Vernonia herbacea as influenced by mineral fertilization and time of harvest. Revta. brasil. Bot. São Paulo 21(3).

11. Proctor JTA, Sullivan JA (2013). Effect of seeding depth on seedling growth and dry matter partitioning in American ginseng. Journal List 37 (2): 254-260.

12. Stauffer MD, Chubey BB, Dorrell DG (1980). Growth, yield and compositional characteristics of Jerusalem artichoke as they relate to biomass production.Conference Paper25:4.

13. Sun X, Panpan S, Lin Z, Jia Z, Yan L, Zhiqin Z (2014). Effect of container growing on growth, development, dry matter accumulation and distribution of herbaceous peony. Acta Horticulturae Zhejiangensis 26(3): 0-632637.

14. Şelaru E (2007). Cultivation of garden flowers. Ed. Ceres, București, pp. 338.

15. Teye E, Asare A P, Amoah RS, Tetteh JP(2011). Determination of the dry matter content of cassava (Manihot esculenta, Crantz) tubers using specific gravity method. ARPN Journal of Agricultural and Biological Science 6(11): 23-28.

16. Traynor J, Mactier R, Colin, Geddes C, Fox JG (2006). BMJ. 333(7571): 733-737.doi:10.1136/bmj.38975.390370.7C.

17. Van Waes C, Baert J, Carlier L, Van Bockstaele E (1998). A rapid determination of the total sugar content and average inulin chain length in roots of chicory (Cichorium intybus L.). J. Sci. Food Agri. 76:107-110.

18. Zubaidah E, Akhadiana W (2013). Comparative Study of Inulin Extracts from Dahlia, Yam, and Gembili Tubers as Prebiotic. Food and Nutrition Sciences.

19. ${ }^{* * *}$ https://www.gardenia.net/plant/cactus-dahliasummer-bulb-of-the-year

20. ***http://www.botanical.com/botanical/mgmh/d/ dahlia02.html 